\title{
进ettsomian a dectures
}

\section{ON}

AMOEBIC LIVER ABSCESS :

ITS PATHOLOGY, PREVENTION, AND CURE.

BY Sir LEONARD ROGERS, C.I.E., M.D., F.R.C.P.LOND., F.R.C.S. ENG., F.R.S., IIEUT.-COLONEL, I.M.S. (RET.)

LECTURE III.*-THE PREVENTION OF AMCEBIC LIVER ABSCESS AND THE RECENT REDUCTION IN ITS PREVALENCE AND MORTALITY.

I HAVE so far dealt with developed amœbic liver abscesses, and although time has not permitted me to go into clinical details, it will be sufficiently obvious that any simple method of preventing such a serious complication of amœbic colitis will be far more beneficial than even the improved methods of dealing with the established condition already described. now proceed to the researches which have enabled me to establish such a method on a scientific basis and to reduce remarkably the number and mortality of these serious cases as compared with earlier days, when indeed the method I advocate was used empirically to a considerable extent in India, although when I commenced my investigations in Calcutta it had fallen very much out of favour-largely I believe, owing to the numerous dysentery cases of the bacillary type, seen during the South African war, in which ipecacuanha was found to be of no use, so that numerous army medical officers on their return to India increasingly relied on the then popular saline treatment of dysentery in place of the Brazilian root. In my first lecture I dealt with the history of the relationship of liver abscess to dysentery, but I reserved until now the consideration of the former use of ipecacuanha in dysentery and hepatitis in India, where its value has so long been known.

Use of Ipecacuanha IN Dysentery aND HEPATITTS IN INDTA.

Ipecacuanha, or Brazilian root, was first brought to Europe for use in dysentery in 1658, and was apparently given in India as early as 1660 ; according to Norman Chevers, Abercrombie used the drug in large doses in Madras as early as 1807, although a little later Annesley advised only 1 to 3 gr. doses, but mentions that some doctors gave 30 to $60 \mathrm{gr}$., and Twining gave 6 gr. with blue pill, both reporting good results. Curiously enough, Annesley in "hepatic dysentery" preferred antimony, while in 1871 W. C. Maclean records using tartar emetic in hepatitis. Docker is usually credited with having reintroduced large dose of ipecacuanha in dysentery in 1859 among British troops at Mauritius with brilliant results ; but I find that Edmund Parkes advocated 30 to $60 \mathrm{gr}$. of the drug in this disease as early as 1846, although in hepatitis he advised bleeding, mercury pushed to salivation point, and purges. Of still greater interest from my present point of view is the use of ipecacuanha in hepatitis, which, as far as I have been able to ascertain, was introduced by Maclean, although in a paper he published in the Indian Annals of Medical Science of 1854 on the Abuse of Mercury in Hepatic Disease, declaiming justly against the then widely prevalent production of salivation with this metal, he does not mention ipecacuanha, but advises strict diet, cutting off all alcohol, and saline purges for hepatitis. However, in his article on Suppurative Inflammation of the Liver, in Reynolds's "System of Medicine" of $1871,{ }^{16}$ he states that for years past in his Netley lectures on Tropical Diseases, published later in 1886 , he had advised 20 to $25 \mathrm{gr}$. doses of ipecacuanha in acute hepatitis with the object of

* Delivered on Feb. 20th, 1922. Lectures I. and II, appeared in THE LANCET of March 11 th and $25 \mathrm{th}$, respectively. preventing suppuration taking place, and he remarks regarding the use of the drug in dysentery : "How this remedy, always deserving the name of a specific, came to be superseded by calomel and opium in the treatment of dysentery in the East is one of the most curious questions in the history of tropical medicine." This observation might justly be applied to the replacement to a great degree of ipecacuanha by salines in dysentery, and by ammonium chloride in hepatitis, at the beginning of the present century, although Chevers in 1886 had fully endorsed Maclean's opinion of the value of this old drug in both diseases; but it is now clear that such violent fluctuations in treatment were inevitable in India as long as amobic dysentery remained unrecognised and one protagionist was dealing mainly with this form and another with the bacillary type. Although Maclean's empirical use of ipecacuanha in hepatitis fell into undeserved neglect two decades ago, it was not altogether laid aside ; Sir Patrick Manson, in particular, from the first issue of his book in 1898 consistently advised large doses of the drug when hepatitis is associated with dysentery, and has resisted the milder treatment with salines and ammonium chloride, which he advises for "tropical liver" unassociated with dysentery, while long before he recognised amœbic dysentery as a distinct form of disease he recommended ipecacuanha in dysentery cases invalided home from the tropics. The not infrequent cases of hepatitis going on to liver abscess without symptoms or history of dysentery, however, would be liable to escape the drug even under such a system of treatment, and in order to get the full benefit of its specific action a simple method of early clinical recognition of the more chronic forms of the disease was required, which I found in the blood changes now to be described.

\section{Value of the Blood Changes in Early Recognition} of Amoebic Hepatitis.

Having thus cleared the ground, I will continue the description of the researches leading to the differentiation of what I have termed the presuppurative stage of amcbic hepatitis and to its cure by ipecacuanha, with resulting prevention of abscess formation and the necessity for surgical interference. Coincidently with my studies of the ætiology and treatment of tropical liver abscess I was working at the differentiation of tropical fevers by blood changes ; in my spare time for a number of years I kept shorthand notes and four-hourly temperature charts of between two and three thousand cases, mainly at the European hospital, including 1350 consecutive fever admissions in which I examined the blood within two. years. When I began this work in 1901 it may safely be said that about 90 per cent. of the fever cases were diagnosed and treated as malarial, although I found only one-seventh of them were really so ; kala-azar and seven-day dengue-like fever had not at that time been differentiated, and among the fevers then nearly always confused with malaria were the more chronic amoebic hepatitis cases, which were always treated with quinine, with or without ammonium chloride, until the clinical signs of an insidiously forming liver abscess obtruded themselves on the attention of the physician. It was, of course, known that liver abscess produced a leucocytosis ; but with no pathologist and two overworked resident medical officers in sole charge of some 200 medical and surgical beds, blood counts could rarely be made. A succession of brother medical officers gladly gave me every opportunity for my investigations; I still have my slips with the notes and blood counts and tables with all the cases classified in series, and it is of great interest to note that none of the hepatitis cases, including those going on to abscess formation while in hospital, during nearly four years had been treated with ipecacuanha, and the same was true of the Medical College Hospital; thus it is clear that at that time in Calcutta that specific drug had been superseded by ammonium chloride in hepatitis, just as Maclean 30 years before complained it had been replaced in dysentery by calomel and opium. 
In my earlier fever work I was particularly on the look out for liver abscess cases for trying my aspiration and quinine injection method of treatment; consequently I made blood counts in cases of hepatitis, and in $1905^{17}$ published my first paper on the blood changes in hepatitis and liver abscess. The first five cases I then dealt with were admitted for hepatitis not going on to suppuration, and only two of them showed the very slight increases of leucocytes of 10,250 and 11,500 respectively. On the other hand, in 11 cases going on to abscess formation, leucocytosis varying from 12,750 to 38,500 was present, and the exceptional case showed 8625 with only $2,860,000$ red corpuscles, or a relative increase of the white corpuscles; the significance of this increase I overlooked at the time, but subsequently recognised that it may be diagnostic of inflammatory changes in the liver. I have since reported a case of liver abscess pointing through the abdominal wall, with great relief of the original tension, in which leucocytosis was absent, but here the diagnosis was not in doubt. The two cases with over 35,000 leucocytes were very acute and fatal multiple ones, such very high counts being of bad prognostic import in amœbic hepatitis and in amœbic dysentery. On the contrary, in two of the most chronic and insidious cases leucocytosis was absent on admission for ferer of obscure nature, but developed later while on ammonium chloride, which $I$ have never seen do the slightest good in hepatitis. This paper was also noteworthy for the record of my first case in which acute hepatitis with leucocytosis was recovered from without abscess formation, under large doses of ipecacuanha given on my advice, based on the following simple but scientific considerations.

Rationale of $U$ se of Ipecacuanha in Acute Hepatitis to Prevent Amobic Liver Abscess.

I had already proved that tropical liver abscesses always contained amobæ, but rarely pyogenic bacteria, so was almost certainly caused by the amobæ; that they were always preceded by amcebic ulceration of the colon, most frequently limited to the upper fourth of the large bowel and therefore clinically latent; that amobic dysentery was very common in Calcutta, where it had not previously been recognised. I had convinced myself that ipecacuanha-so long believed in by the most eminent physicians practising in India-was indeed a specific for the amœbic variety, although useless in the bacillary form so common in Indian gaols, where liver abscess is rare; and, lastly, I had found that slight degrees of leucocytosis might occur in cases of hepatitis before suppuration had taken place, which were diagnostic of amobic hepatitis in what 1 designated the presuppurative stage. I therefore argued that although such cases might or might not give a history of previous dysentery, and very rarely showed actual symptoms of dysentery during the insidious development of a tropical liver abscess with more or less definite signs of hepatitis, yet I knew from my extensive experience of post-mortems on fatal liver abscess cases that latent amobic ulcers must be present in some part of the large bowel, which could be healed by full doses of ipecacuanha with conserfuent eutting off of the source of the amobic infection of the liver and the prevention of abscess formation, for which purpose Maclean and Cherers had empirically used it 30 years before.

Establishment of Early Diagnosis and Cure of the Presuppurative Stage of

AMCEBIC HEPATITIS.

It was not until two years later, in $1907,{ }^{18}$ that I was able to record a convincing series of such successful cases, which included the 15 cases of hepatitis I met with among the 1350 consecutive fever admissions, or just over 1 per cent. ; it was not surprising they had not been differentiated by busy clinicians in the absence of blood examinations. In three cases there was a previous history of dysentery and symptoms of hepatitis on admission with leucocytosis and fever for 15,34 , and 41 days respectively before ipecacuanha was given, but the temperature finally fell to normal in two to four days after its administration with rapid cessation of all hepatic symptoms. In eight cases there was no history of dysentery, and in only one that of diarrhcea, but symptoms of hepatitis were wellmarked. Three of these eight were early cases who recovered without ipecacuanha, although in two of them leucocytosis and well-marked clinical signs led to negative exploratory puncture being performed for liver abscess, and in one case the abdomen was also opened, but no abscess found. I have records of a similar case in which an abscess had to be opened some months later. In these three cases the fever only ceased after 34,39 , and 49 days respectively, which is a great contrast to the average fever duration of five days after the exhibition of the specific drug in the other 12 cases. The remaining five cases of this group, with leucocytosis in four of them, all lost their fever within one to six days under ipecacuanha with rapid subsidence of the hepatic symptoms. Four cases were admitted for fever of doubtful origin without any acute hepatic symptoms or history of previous dysentery, the true nature being only cleared up by my finding leucocytosis, when ipecacuanha was given and the fever subsided, although more slowly in two of them than in the more acute form. This important class illustrates the chronic forms of amobic hepatitis, which are most liable to be overlooked, and under any other treatment are very likely to result in most insidious liver abscess formation. Taking the whole series, it is especially noteworthy that less than 12 of the 15 were unassociated with dysentery, so that even according to Sir Patrick Manson's last edition they would still not be treated with ipecacuanha; yet I was able to recognise them as probably amoebic in origin by the blood changes, and to treat them successfully with that drug, which appears to me to be a considerable advance even on the most enlightened previous use of ipecacuanha in the prevention of liver. abscess.

Comparison of the leucocyte counts of this series with those of the 1905 cases shows a most instructive difference, although both series relate to hepatitis without clinical signs of liver abscess formation, the only essential difference between them being that the later cases were alone treated with ipecacuanha. Of the 21 cases admitted with hepatitis in the first series, and treated with quinine and ammonium chloride, no less than 16 went on to suppuration, including every case in which the total leucocytes exceeded 12,000, and one with a relative leucocytosis while, on the contrary, of the 12 cases of the second series treated with ipecacuanha no less than 11 showed well-marked leucocytosis, yet every one of them rapidly cleared up under the ipecacuanha treatment without going on to suppuration. I think there can be no doubt that suppuration was actually averted in most of them by that drug, especially as in three of them the hepatic symptoms were so acute that exploratory puncture for liver abscess was actually performed.

\section{Significance of Differential Leucocyte Count in Amoebic Hepatitis.}

Another point I have drawn attention to is that in large single amoebic liver abscess a well-marked leucocytosis is commonly accompanied by only a slight increase in the percentage of the polynuclears as compared with those usually met with in parenchymatous inflammations such as pneumonia. Thus, in not one of 19 hepatitis cases did the polynuclear percentage reach 90 , while in 13 of them it was only between 70 and 80 and may be within the normal limits, especially in the more chronic cases. This is also the case even when the amobic infection spreads through the diaphragm to involve the base of the right lung, when I have found it of diagnostic importance in differentiating the condition from a basal pneumococcal pneumonia, in which the polynuclears usually exceed 90 per cent. This is also a matter of practical importance; I have repeatedly seen amœbic hepatitis producing fixation of the diaphragm and even a shadow in the base of the right lung, clear up under ipecacuanha. In acute multiple liver abscesses with sloughing amobic dysentery, however, the 
polynuclear percentages are usually between 80 and 90 , although very rarely over the latter point, while in such cases the total leucocytes may number from 30,000 to 50,000 , which carries a very serious prognosis, although I have several times seen cases of very acute hepatitis with counts of from 25,000 to 30,000 recover under ipecacuanha without evident abscess formation.

Chronic Non-Suppurative Amobic Hepatitis and Cirrhosis of the Liver in India.

I next pass on briefly to consider the evidence which has convinced me that the usual cause of the numerous cases of cirrhosis of the liver met with in Calcutta is a still more chronic form of amcbic hepatitis not going on to abscess formation, although this factor appears to have escaped the vigilance even of Norman Chevers and of Edward Goodeve, the eminent Calcutta physician who contributed the article on cirrhosis of the liver to Reynolds's System of Medicine. In a laborious analysis of nearly 5000 Calcutta post-mortems, which occupied my odd moments for a number of years, I found ${ }^{19}$ that the 37 years' records dealt with showed the remarkably high rate of 6.9 per cent. of well-marked cirrhosis of the liver, including latent cases in patients dying of other diseases, which is seven times as high as in large Berlin series of autopsies. As the disease is common in Mahomedans, who are prohibited by their religion from taking alcohol, we must look to some other cause of its great prevalence in India; it has also been commonly found by Sutherland in the Punjab. The great majority of the cases were of the hobnail multilobular variety, which was also common in chronic kala-azar cases in addition to the smoothsurfaced intracellular variety $I$ have described in that disease, ${ }^{20}$ which was not recognised in the earlier records. On working out the percentages of the principal complications, granular kidney was found in 28 per cent. of fatal cirrhosis cases, and in 13 per cent. of latent cases, in accordance with the well-known relationship of these two diseases. Dysentery, however, was found in $25 \cdot 6$ per cent. of the fatal cases and in no less than $30 \cdot 1$ per cent. of the latent onesa most remarkable fact. The more closely I analysed the data, the more definite appeared the relationship between the two diseases. On dividing the series into three equal periods of time, the ratio of cirrhosis to dysentery cases only varied between 1 to $3 \cdot 3$ and 1 to 3.8 ; on tabulating all forms of ulceration of the stomach and bowels other than tuberculous, no less than 41 per cent. of cirrhosis cases showed ulceration of some part of the gastro-intestinal mucous membrane, while on excluding recent dysentery and adding together chronic ulceration of the colon and scars of old dysentery, I found evidence of chronic bowel lesions, which might have preceded the cirrhosis, in 37.8 per cent. of cirrhosis cases, other than those complicating kala-azar and in 33.3 per cent. of kala-azar multilobular cirrhosis. Once more, in the advanced fatal cirrhosis cases, scars of long antecedent dysentery were more frequent than actual chronic ulcers, while the reverse was the case in the more recent latent cirrhosis cases-precisely what might be expected if the cirrhosis was secondary to the dysentery, although this point did not occur to me until after I had worked out the tables. One possible fallacy remained to be excluded-namely, that dysenteric ulceration in Calcutta might be equally common in the general run of cases as in the cirrhosis ones; to test this I specially analysed the bowel lesions in approximately one-third of the cases in each equal period of time, with the result that dysenteric lesions had been recorded in almost exactly twice as high a proportion of the cirrhosis cases as of the total cases, thus confirming the intimate relationship between the two.

There remained the question of the form of dysentery related to cirrhosis of the liver, which is difficult to estimate from the old records, but fortunately I had a further eight years' post-mortem experience in Calcutta after I had worked out the above data, during which I closely examined the large bowel for scars of old dysenteric ulcers ; I can now testify that I found evidence of former chronic amobic dysentery in something like three-fourths of cirrhosis of the liver cases-always of the amobic variety when ulcers were present often in addition to old pigmented scars. Nor is it difficult to account for the very close relationship between the two diseases when we recall that in the usual chronic form of tropical abscess the amoeba produces the formation of a dense fibrous wall around the pus through inciting a chronic form of inflammation. They reach the liver through the portal vein, to be distributed in its small interlobular branches, producing clotting within them and acute hepatitis when numerous, while they must frequently be carried to the liver during the course of chronic amobic colitis, often of many years' duration in the common relapsing cases, which were seldom efficiently treated until very recently, while a few cases are still incurable even with emetine treatment, so that it is easy to understand how long-continued amobic irritation of the portal branches may eventually lead to the increase of the interlobular fibrous tissue to such an extent as to produce an actual cirrhosis of the organ. Clinically we not rarely meet with repeated attacks of hepatitis, which until recently occurred in the British troops in India from eight to ten times as frequently as actual abscess formation, while it is of interest to note that Waring and Morehead have also reported several cases of abscess of the liver in a cirrhosed organ, so that this suggestive combination is by no means very rare.

Yet one more piece of evidence is furnished by the blood counts I have recorded in cirrhosis of the liver in Calcutta, ${ }^{21}$ showing an actual leucocytosis in nine and a relative one in six more out of 24 cases examined, while in 13 of them the often incomplete notes gave a history of previous dysentery. Two of the cases showed leucocyte counts of 30,000 and 33,250 respectively, with over 90 per cent. of polynuclears, and both patients died rapidly of acute cholæmia, probably due to terminal bacterial portal infections; but the remaining cases showed moderate degrees of leucocytosis, with differential counts very similar to those I found in suppurative and presuppurative amœebic hepatitis as well as in many cases of amoebic dysentery itself-surely a very remarkable coincidence, unless my view is correct that many of the frequent Calcutta cirrhosis cases are amobic in origin, while the matter is of some practical importance now that chronic amobic hepatitis can be recognised early by the blood changes and can be cured by simple medical treatment, and so prevented from going on to produce an incurable cirrhosis of the liver.

\section{"Tropical Liver" an Entity?}

The latest edition of Sir Patrick Manson's classical work on tropical diseases reproduces a graphic description of "tropical liver," and advises aperients and ammonium chloride in its treatment unless it "is associated with dysentery," when " should it resist these milder measures hypodermic injections of emetine" are advised. In view of the fact that in three-fourths of my 1907 geries of hepatitis resolving in a few days on ipecacuanha, as well as in very many subsequent cases, there was no history whatever of dysentery, I cannot help thinking that the survival of "tropical liver" from writings nearly a century old is fraught with danger, having probably been largely responsible for the development of so many cases of liver abscess in India under ammonium chloride treatment up to a little more than a decade ago ; it is very interesting to note that such a warm advocate of ipecacuanha in acute hepatitis as Norman Chevers uttered the same warning in 1886, when he wrote : "I confess I know nothing of that mysterious disease called liver. . . . I suspect that much of this notion has come down traditionally, from old times." Abuse of alcohol doubtless often does affect the liver in the tropics as elsewhere, while it only too frequently powerfully predisposes to the development of liver abscess in persons having active or latent 

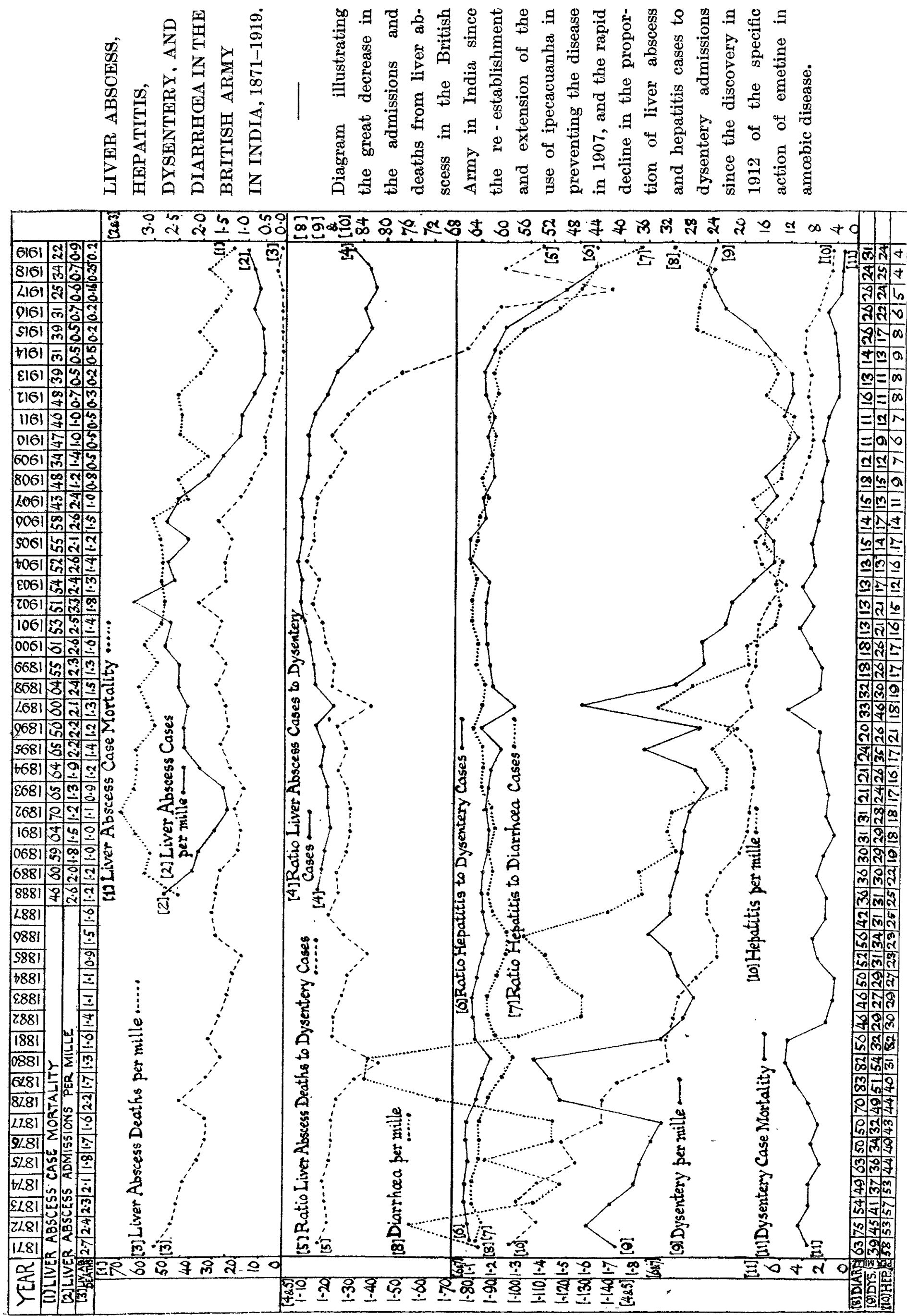
amœbic colitis, although they may also occur in teetotallers; the remarkable immunity of women and children to liver abscess is best explained by the fact that they are much less addicted to alcohol-and, also, I think, by the fact that they are less exposed to amoebic infection in their homes than are the males travelling about on their duties in the insanitary tropics.

1 therefore urge that in tropical and sub-tropical countries, even in the complete absence of any clinical association with dysentery, all liver affections with fever or leucocytosis, actual or relative, should at once be treated with emetine, and that so-called "tropical liver" should never be diagnosed and treated with aperients and ammonium chloride, \&c., until amobic disease has been absolutely excluded, which can seldom be done without the use of the specific remedy for that disease. The following is a striking example of the development of a liver abscess under ammonium chloride treatment. The patient was admitted after three weeks' fever of uncertain nature, and a few days later signs of hepatitis with leucocytosis led to exploratory laparotomy and puncture of the enlarged congested left lobe of the liver with negative result; saline purges and ammonium chloride were continued, but four weeks after admission at a second laparotomy an abscess was opened in the very part of the liver which had been proved free from suppuration three weeks before. The case terminated fatally. The following case, treated by the same surgeon with ipecacuanha on my advice, presents a striking contrast to the last. The patient was admitted for dysentery, which subsided in ten days under castor oil mixture, but seven days later he developed such acute hepatitis with high fever, pain in the right shoulder, fixed right side of the diaphragm, and a slight shadow in the right lobe of the liver with $\mathrm{X}$ rays that the surgeon confidently diagnosed liver abscess, and he was only persuaded with much difficulty by myself and a physician who had seen several equally acute casesrecorded in my 1907 paper-clear up under ipecacuanha to give that drug first, as the patient had suffered from recent dysentery, before operating. In two days the pain in the liver had ceased, and in three more the temperature fell to normal, all signs of liver abscess disappearing, and complete recovery resulted without any operation. Such cases are now well known to many medical men, but it is of interest to record that as a result of watching the two cases just narrated Lieut.-Colonel H. W. Filgrim, for many years superintendent of the Calcutta European Hospital, under whose care they were, in a debate on the subject several years later, courageously stated that in past years he had seen many cases of liver abscess develop while under ammonium chloride treatment which he was subsequently convinced could have been saved from that serious complication by large doses of ipecacuanha. During the four years since the introduction of my methods out of a yearly average of 200 dysentery cases, nearly all treated with ipecacuanha, not a single case developed hepatitis, and out of an average of 82 hepatitis cases treated in the same way none developed liver abscess, while the admission to his wards with suppuration already established in the liver bad fallen to about one-third of the previous number.

Recent Reduction in Incidence and MortaltTy OF AMCEBIC LIVER ABSCESS.

If all $I$ have said regarding recent advances in the treatment and prevention of amobic liver abscess is true, it ought by this time to be possible to produce definite evidence of a reduction in the frequency and mortality of the disease, especially in the hospitals in which I carried out my researches. As a matter of fact, as early as 1914 I recorded ${ }^{22}$ the figures of the Calcutta European Hospital for six years before and six years after the publication of $\mathrm{my} 1907$ paper on the prevention of liver abscess, while $I$ am indebted to Iieut.-Colonel E. E. Waters, I.M.S., for the subsequent data, which are briefly summarised in Table I.
Thus the yearly cases per mille of the total admissions has fallen to about one-half and the deaths to less than one-third of the former rate, while the case mortality has also declined by nearly one-half, in spite of the earlier rate having been low owing to the inclusion of some cases treated by my method.

TABLE I.

\begin{tabular}{c|c|c|c|c|c|c|c}
\hline Years. & $\begin{array}{c}\text { No. of } \\
\text { cases. }\end{array}$ & $\begin{array}{c}\text { Yearly } \\
\text { average }\end{array}$ & $\begin{array}{c}\text { Per } \\
\text { mille } \\
\text { of } \\
\text { admis- } \\
\text { sions. }\end{array}$ & $\begin{array}{c}\text { No. of } \\
\text { deaths }\end{array}$ & $\begin{array}{c}\text { Perly } \\
\text { average } \\
\text { mille } \\
\text { of } \\
\text { admis- } \\
\text { sions. }\end{array}$ & $\begin{array}{c}\text { Case } \\
\text { mor- } \\
\text { tality. }\end{array}$ \\
\hline $1901-06$ & 69 & 11.5 & 3.9 & 30 & 5.0 & 1.7 & 43.5 \\
$1907-21$ & 103 & 7.8 & 2.4 & 24 & 1.6 & 0.5 & 23.3 \\
\hline
\end{tabular}

It was also well known long before I left India that the disease had become considerably less frequent among the India patients treated in the Calcutta Medical College Hospital ; unfortunately, the surgical registrar was unable to provide me with figures of either admissions or deaths from liver abscess, so I am unable to prove it statistically.

Dr. A. L. Gregg has kindly supplied me with the admissions and deaths from liver abscess and the admissions for hepatitis not going on to abscess from 1904 to the end of January, 1922, in the London School of Tropical Medicine Hospital, which I have divided up into the periods shown in Table II.

TABLE II.

\begin{tabular}{l|cc|c|c|c|c|c}
\hline & Years. & $\begin{array}{c}\text { Hepa- } \\
\text { titis. }\end{array}$ & \multicolumn{3}{|c|}{ Liver abscess cases. } \\
\hline & $\begin{array}{c}\text { Reco- } \\
\text { vered. }\end{array}$ & Total. & Cured. & Died. & $\begin{array}{c}\text { Read- } \\
\text { mitted. }\end{array}$ \\
\hline (A) & $1904-07$ & $\ldots$ & 4 & 13 & 5 & 8 & 2 \\
(B) & $1908-12$ & $\ldots$ & 6 & 15 & 10 & 5 & 4 \\
(C) & $1913-22$ & $\ldots$ & 9 & 14 & 14 & 0 & 0 \\
\hline
\end{tabular}

(A) Before revival of ipecacuanha treatment. (B) Before emetine treatment. (C) After establishment of emetine treatment.

Thus in the first period the deaths averaged two yearly, and in the second period one, but during the last nine years 14 consecutive cases have recovered, no case has been lost, and no case readmitted for further treatment; a very satisfactory record.

Recent Reduction in Incidence and Mortality from Liver Abscess in the British Army in India.

In the medical returns of the British Army in India, published yearly in the reports of the Sanitary Commissioner with the Government of India, we have ideal data for a study of the yearly variations in the incidence and death-rates per mille among 50,000 to 80,000 men, with the aid of which I have plotted out the curves shown in the diagram (see figure), which present features of great interest. Unfortunately, prior to 1888 liver abscess cases were included under hepatitis and congestion of the liver, although minute details of several hundred minor affections were tabulated yearly, but subsequently to the separation in the returns of liver abscess the deaths from inflammation and congestion of the liver rapidly fell to practically nil, so that it is safe to assume that the fatalities under those headings in the earlier years were essentially due to liver abscess; thus complete curves for the whole period can be plotted out of the annual deaths per mille from liver abscess in curve 3 , and of the ratio of fatal liver abscess to dysentery admissions in curve 5 , for the 49 years from 1871 to 1919 ; before 1871 the tables refer to Bengal only, se are not strictly comparable.

Relation of Hepatitis to Dysentery and Diarrhoea

Curve 8 shows the diarrhoa rates per mille, curve those of dysentery, and curve 10 those of hepatitis for the full period; they reveal a gradual decline of all three up to about 1904 , varied by occasional sudden high rises of both bowel diseases without any marked 
increases in the hepatitis rates, such as in 1879-80, 1885,1895 , and 1897 , thus showing no relationship between the epidemic rises in bowel diseases and the incidence of hepatitis. In curve 11 , representing the yearly case mortalities of dysentery, it will be seen that each epidemic rise was accompanied by a rise in the case mortality; curve 5 illustrates the ratio of fatal liver abscess and hepatitis cases to dysentery admissions, and reveals a decline in the ratio with each epidemic rise of dysentery. All these facts indicate these epidemics of bowel fluxes to have been bacillary in nature, including the diarrhoea risesa point of considerable epidemiological interest.

The close relationship of the dysentery and diarrhoea curves, apart from the occasional epidemic rises, is further emphasised by a glance at curve 6 , representing the ratio of hepatitis to dysentery cases, and curve 7 , showing the ratio of hepatitis to diarrhoea admissions, for they reveal the remarkable high ratio of one case of hepatitis to each one to two cases of either bowel disease, while the two curves run a remarkably parallel and even course for 44 years up to 1914, and then fall together, clearly proving that hepatitis in India is just as closely related to diarrhoea as it is to dysentery. In $1913^{2}$ I recorded curves showing an intimate relationship between the seasonal incidence of dysentery and diarrhcea to hepatitis cases in two large Calcutta hospitals - the two forms of bowel diseases increasing greatly in the rainy season and being followed by the maximum incidence of hepatitis two months later-and I urged that many diarrhoea cases were really amcebic colitis without definite dysenteric symptoms, a view strikingly confirmed by the curves under discussion. Moreover, in an analysis of the clinical diagnoses and post-mortem findings in 1000 consecutive autopsies I performed in Calcutta, I pointed out ${ }^{23}$ that in no less than 50 per cent. of fatal amobic ulcerations of the large bowel the disease had not been recognised as dysentery at all, by far the commonest erroneous diagnosis in the wards having been chronic diarrhoea or tuberculous diarrhcea Obviously just such cases of amøbic colitis-as it might well be called-are most likely to escape treatment with the specific remedy for amchic disease, and to give rise later to amobic hepatitis and liver abscess, so too much emphasis can hardly be laid on this important relationship of tropical diarrhoea to amobic hepatitis, which should lead to the use of emetine in recurring diarrhoea as well as dysentery in such countries.

We may now proceed to consider the incidence and mortality of liver abscess from 1888 to 1919 as illustrated by the upper three curves of the diagram, curve 1 showing the yearly case mortality, curve 2 the admission-rates, and curve 3 the death-rates per mille, which is continued back to 1871 with the figures of the deaths per mille from hepatitis and congestion of the liver, as already explained. In the first place, during the five years from 1888 to 1892 the admission-rate for liver abscess in curve 2 fell steadily without any marked fall in the deaths per mille, owing to a great rise in the case mortality from 46.5 to 70.3 per cent.- the latter possibly due to increasing resort to open operation, with the spread of antiseptic treatment. This decline in the liver abscess incidence coincided with a similar fall in that of hepatitis, dysentery, and diarrhoea, as shown in the lower part of the diagram; but it was followed by a prolonged steady rise in the incidence and mortality of liver abscess from 1894 to 1907 , with its maximum in 1902 , although during this period the hepatitis rate (curve 10) showed a decline followed by a fairly steady low incidence, and, apart from the epidemic rises between 1895 and 1897 , the diarrhoa and dysentery rates also declined, following a similar course to hepatitis. Consequently the ratio of liver abscess admissions and deaths to dysentery, shown in curves 4 and 5 , also rose steadily during this period, the admission-rates rising from 1 to 13 cases of dysentery to the very high ratios of 1 to 7 to 1 to 5 from 1902 to 1907 , and the ratio of hepatitis deaths to dysentery admissions from 1 to 25 up to 1 to 12 to 1 to 9 during the same period, or about double those of the earlier 25 years from 1875 to 1899 -very remarkable facts which I believe are explained by the greatly increased use of salines, in the place of ipecacuanha, in India following the South African war.

We next come to the striking change in the curves beginning in 1908, from which date there was a sharp fall in both the admission- and death-rates per mille from liver abscess, curves 2 and 3 , together with a slighter one in the hepatitis rate, curve 10 , although the dysentery and diarrhoea rates, curves 8 and $\theta$, showed only slight fluctuations up to 1914, after which they both presented a steady and marked rise from 1915 to 1919 without the sudden peaked rises of the earlier epidemics of bacillary dysentery, and probably due in large part to an increased prevalence of the amœbic variety. Nevertheless, during these last five years of increased bowel fluxes the hepatitis rate fell steadily to by far the lowest point of the whole 49 years' curve, the liver abscess admission-rate showed only a very slight rise with an average rate of less than one-third of that from 1895 to 1907 , while the liver abscess death-rate remained at its lowest point of one-sixth of the earlier figures. Again, if we compare the rates of the last eight years, after the fall had become well established, with those of the 13 years up to 1907 before it commenced, we find a reduction in the admission-rate for liver abscess of 74 per cent. and in the death-rate of 84.3 per cent., which is of very great significance when we recall that it was in 1907 that I recorded conclusive evidence that the presup. purative stage of amobic hepatitis could be diagnosed by blood examinations and also rapidly cured, and thus prevented from going on to liver abscess formation, by ipecacuanha, and it is equally significant that the steady fall in the admission-rates for hepatitis, in spite of a great rise in the prevalence of dysentery and diarrhœa, commenced in 1916, when the emetine treatment of dysentery was both well established and the shortage of the drug during the earlier stages of the war had been largely overcome.

It should be mentioned that in working out the dysentery curve I found it essential to accuracy to combine the cases returned as "dysentery" and as " colitis," in view of the extraordinary fact that the proportion of cases returned as colitis rose from under 1 per cent. prior to 1903 to about 60 per cent. in some recent years, while it is stated in the reports that many of the colitis cases were mild dysenteries, some being actually complicated with liver abscess, so that to have plotted out only the dysentery returns would have shown a fictitious reduction during the last 14 years.

There remain to be considered the remarkable declines in the ratio of liver abscess admissions and deaths to dysentery admissions, curves 4 and 5 , and of hepatitis to dysentery and diarrhoea admissions, curves 6 and 7 , during the last few years, the latter having been remarkabily high and fairly stationary for the previous 40 years. Curve 4 shows the ratio of liver abscess to dysentery admissions from 1888 to 1919 , during the first ten years of which the rate was comparatively low as compared with the next 14 years, while the last eight years, since I established the value of emetine in 1912, show a remarkable

TABLE III.-Ratio of Liver Abscess to Dysentery Cases.

\begin{tabular}{|c|c|c|c|c|c|c|}
\hline \multirow{2}{*}{ - } & \multicolumn{3}{|c|}{-} & \multicolumn{3}{|c|}{ Ratio of deaths. } \\
\hline & Max. & Min. & Aver. & Max. & Min. & Arer. \\
\hline 1888-1897 & $1-12$ & $1-21$ & $1-16$ & $1-21$ & $1-35$ & $1-25$ \\
\hline 1898-1911 & $1-5$ & $1-12$ & $1-8$ & $1-9$ & $1-25$ & $1-16$ \\
\hline $1912-1919$ & $1-17$ & $1-37$ & $1-29$ & $1-34$ & $1-136$ & $1-82$ \\
\hline
\end{tabular}

decline. Table III. shows the maximum, minimum, and average figures (which are not entered in the diagram for want of space) for these three periods of time of the ratios of liver abscess admissions and of deaths to the dysentery admissions.

It appears from these striking figures that in the second period the average ratio of liver abscess 
cases to dysentery admissions rose to double that of the first period, while after the introduction of emetine the proportion fell to from 1 to 8 to 1 to 29 , or less than one-third, while the ratio of liver abscess deaths to dysentery admissions showed a nearly similar increase in the second period, only to fall to one-fifth in the last eight years, the combined effects in the reduction of the incidence and of the mortality of curves 2 and 3 being thus brought out in curve 5 .

Lastly, curves 6 and 7 show a precisely similar remarkable decline in the ratios of hepatitis to dysentery admissions from an average of approximately 1 to 1.5 for 44 years up to 1914 to 1 to 5 during the last five years, and the ratio of hepatitis to diarrhcea admissions from 1 to 2 to 1 to 6 , or a threefold reduction in both instances, these remarkable declines also occurring when emetine was well established and readily available.

Further comment seems unnecessary, as, taking the diagram as a whole, it would be difficult to conceive of more conclusive evidence-first, of the reduction in the incidence and death-rate of liver abscess in the British Army in India from the date I showed it to be an easily preventable disease; and, secondly, of the fall in the proportion of liver abscess and hepatitis cases to dysentery, following the establishment of emetine as a specific remedy for amobic ulceration of the large bowel.

Lastly, the case mortality of liver abscess has steadily fallen, as shown in curve 1, beginning in 1907, which happened to be the year immediately following the publication of my paper on the cure of liver abscess by repeated aspiration and injection of amobicidal drugs into the cavity without drainage. The figures in Table IV. illustrate the point.

TABLE IV.

\begin{tabular}{|c|c|c|c|}
\hline $\begin{array}{l}\text { Liver abscess case } \\
\text { mortality - }\end{array}$ & Max. & Min. & Aver. \\
\hline $1888-1906$ & $70 \cdot 3 \%$ & $46.5 \%$ & $56.5 \%$ \\
\hline $1907-1919$ & $47 \cdot 8 \%$ & $22 \cdot 5 \%$ & $37 \cdot 1 \%$ \\
\hline
\end{tabular}

These figures show a reduction of 34.4 per cent. in the average case mortality on the previous rate; while during the last four years, with good supplies of emetine, the death-rate has been only one-half of the former case mortality, probably because of the inrreasing use of the aspiration and emetine method, although the fact that the last-mentioned rate is still double that of $\mathrm{my}$ method of treatment indicates that it is still far from having been generally adopted, so a further decline may still be looked for, and will, I trust, be hastened by the foregoing demonstration of the great saving of life already brought about in the British Army in India in the last decade.

Medicinal Treatment of an Already Formed Amobic Liver Abscess.

If two decades ago anyone had suggested that already formed single or multiple liver abscesses could be cured by simple drug treatment he would probably have been told that the age of miracles has long gone by. Nevertheless, I have long thought, and now have conclusive evidence, that it may indeed take place, under emetine treatment. I have already reported a case of very acute hepatitis clearing up under emetine, in which the patient returned to hospital a few months later and died of a totally different disease; I found post mortem an encysted liver abscess free from amøbæ or bacteria. Cases have also been recorded of patients refusing operation for obvious pointing liver abscess, who eventually recovered under emetine without operation, the abscess gradually subsiding, although in such cases it is clearly advisable to hasten the recovery by removing the sterile pus by aspiration. A useful practical help in deciding how often it is necessary to repeat such aspirations is the leucocyte count, as when a previously present leucocytosis disappears aspiration is usually negative, and it is unnecessary to repeat it.
Of much greater practical importance is the further question, Can small multiple amœbic liver abscesses, not amenable to surgical measures, be cured by emetine? The fact that a fibrous-walled liver abscess containing several ounces of pus, such as that just mentioned, may encyst as a result of the destruction of the causative amoebæ in its walls, suggests to my mind that the small early acute multiple amcbic abscesses should prove still more amenable to the specific action of ipecacuanha and emetine, and $\mathbf{I}$ have long felt that some at least of the considerable number of extremely acute hepatitis cases with from 25,000 to over 30,000 leucocytes, which I have seen recover under this treatment, must have passed beyond the presuppurative stage, and that early multiple abscesses, hitherto thought to be incurable, had been resolved, but it was only during my last year in India that I obtained ocular proof of this occurrence. What emetine treatment of a week's duration can do in the way of rewoving the extensive gelatinous infiltration of the coats of the large bowel in amcebic dysentery. All the infiltration and thickening completely disappeared, a result I never saw under the former ipecacuanha treatment, and the different coats were, as it were, dissected out by the destruction the disease had brought about, only the peritoneal coat remaining in places, with the inevitable result of fatal perforation of the cæcum and post-colic abscess, proving the great original severity of the case. If such a remarkable absorption of the diseased tissues can be brought about in the bowel wall is it unreasonable to suppose that early multiple amœbic liver abscesses may similarly be resolved by emetine?

\section{Small Multiple Amabic Liver Abscesses Cured by} Emetine.

I was asked to examine the stool of a female patient suffering from obscure abdominal symptoms and, recognising amœbic dysentery, advised emetine, which was only given for a very short time by the surgeon in charge of the case. Some days later he opened the abdomen, and found the liver studded with numerous small abscesses, from one of the largest of which he removed a drachm or two of thick pus, in which $I$ found amœebr, while it was sterile on culture; emetine was pushed, with the happy result that the patient completely recovered and was in good health a year after when I last heard of her.

This success forms a fitting climax to my 20 years' Calcutta researches on amcbic disease, and finally establishes emetine as probably the most definitely specific drug known to medicine, for its action in this case is surely more remarkable than that of quinine killing the malaria parasites in the circulating blood, and one which may perhaps some day gain for it a corner in the British Pharmacopœia, even if some littleused decoction of hoary antiquity has to be sacrificed to make room for it.

\section{Conclusion.}

I have now completed my task, and I venture to think that the investigations I have described constitute a good example of the value of combined clinical and pathological research, which $I$ was never tired of advocating in India, with the happy result of having been able to found in Calcutta a post-graduate and research School of Tropical Medicine with a staff of about 40 medical men and a special hospital of its own, side by side with a Medical College with another 700 beds-an example which I think even London might follow with advantage; for I have long been convinced that, in the absence of adequate post. graduate teaching, a new generation of medical men must arise before the general public obtain the full benefits of the advances made by research workers. $I$ do not think I can end better than by repeating what I said over a decade ago: "It is already abundantly clear that I did not exaggerate when I wrote that amcoic or tropical liver abscess is an easily preventable disease in the great majority of instances, and the occurrence of amobic suppuration in the liver should cause serious questions in the mind of the medical man in whose hands it has been 
allowed to develop." To this dictum I would now add that in patients coming first under observation with an already formed amobic liver abscess, when. ever possible, the treatment of election should be repeated aspirations and subcutaneous injections of emetine in preference to incision, while when such an abscess has eventually to be opened some form of sterile syphon drainage should be made use of. A little over a decade ago liver abscess was second only to typhoid in its lethal effects on the British soldier in India, causing nearly 100 deaths a year among them, but the death-rate has already been reduced to onesixth by the methods I have so long advocated, and I am convinced that with their more general adoption the loss from this dread tropical disease might be almost completely abolished, and yet another important step taken in rendering tropical and sub-tropical countries nearly as healthy as temperate ones, and thus further materially lightening the white man's burden of raising backward races to a higher plane of civilisation.

References. -5. Brit. Med. Jour., 1903, ii., 706. 6. Moynihan, Sir B. G. A. : Gall-stones and their Surgical Treatment, 1905. Med. Jour., 1908, ii., 1246. 10. Jour. Roy. Army Med. Corps. 11. Ibid., 1906, 1., 1397. 12. Ind. Med. Gaz., 1914, i., 88. 11. Ibid., 1906, i., 1397. 12. Ind. Med. Gaz., 1914, i., 88. 15. Ind. Med. Gaz., 1898, 285. 16. Reynolds's System of Medicine, vol. iii., 321. 17. Brit. Med. Jour., 1905, 1i., 1291 18. Practitioner, 1907, 776. 19. Ind. Med. Gaz., 1911, 47. 20. Ann. Trop. Med. and Parasit., 1908, vol. ii., No. 3. 21. THF 1914, 41. 24. Ibid., 1919, 193. 25. Ibid., 1914, 198. 26. Jour. Trop. Med. and Hyg., 1919,70 .

\section{ASCENDING INFECTIONS OF THE KIDNEY.*}

BY KENNETH M. WALKER, M.B., B.СH. CAMB., F.R.C.S. ENG.,

IECTURER IN VENEREAI DISEASES, ST. BARTHOLOMEW'S HOSPITAL SURGEON WITH CHARGE OF GENITO-URINARY CASES, MTLIER GENERAT, HOSPITAL ; SURGEON TO OUTPATIENTS, ROYAL NORTHERN HOSPITAL.

THE changes that have occurred in our ideas concerning the pathology of urinary infection, afford an excellent example of the way in which judgment tends to swing from one extreme to anothen in a controversial subject. Twenty years ago many of the forms of renal infection that we now have reason to believe are blood-borne were regarded as " ascending." The ascent of infection from the bladder to the kidney by means of direct spread along the surface of the ureter was considered to be a comparatively common event; the old form of Bacillus coli infection of the urinary passages was believed to be an example of such an invasion. However, as the result of further investigations doubt was thrown on the subject. The experimental work of Baureisen, and of Draper and Braasch, showed that organisms cannot ascend the ureter against the urinary current unless certain conditions exist. In order that they may reach the kidney there must be obstruction to the urinary flow and incompetence of the sphincter guarding the opening of the ureter into the bladder. Under such conditions a renal pelvis may be considered to be in open communication with the bladder cavity, and organisms can easily become disseminated in the column of stagnant urine that lies between the bladder and the kidney. Such a condition of affairs is, however, by no means common in urinary practice, and was certainly not present in the great majority of cases regarded up to that time as examples of ascending infection. As a result of this new knowledge on the subject of ascending infection, the pendulum swung to the opposite extreme; all renal infections were now believed to be blood-borne, and the existence of an ascending infection, except as a complication of severe lesions of the urinary tract, was denied. Although this view was undoubtedly

* A paper read before the Section of Urology of the Royal Society of Medicine, Warch 30 th, 1922 . nearer the truth than the previous one, it did not sufficiently recognise the possibility that infection might reach the kidney by other channels than the blood-stream and the lumen of the ureter. Subsequent work has shown that whatever may be its frequency-concerning which there is considerable difference of opinion-infection may take place through the lymphatic system. By such a route the bacteria are carried from the lower urinary passage to the kidney in the absence of all such complications as retention. A pathway-not direct, but offering little difficulty to invading organisms - is provided by the plexus of lymphatics of the ureteral sheath. Along the lymphatic path may travel infection not only from other portions of the genito-urinary tract, but also, on account of the free intercommunication that exists, from neighbouring lymphatic systems, such as that of the large bowel.

\section{The Lymphatic Route of Infection.}

It is $\mathrm{my}$ intention in the following paper to devote myself almost entirely to infection by such a channel. In doing so $I$ do not wish to suggest that in actual practice this route of infection is nearly as common as infection by the blood-stream, but merely to furnish what I believe to be conclusive evidence that such a mode of infection exists and must invariably be taken into account in considering the pathology of any renal infection.

\section{Experimental Evidence.}

The first attempt to demonstrate the ascent of organisms to the kidney by the lymphatics was made by Paladino Blandini, who placed loopfuls of an easily identified organism like Bacillus prodigiosus in the urethra of a guinea-pig, and recovered the same organism from the kidney at the end of 12 hours. If left longer the organisms disappeared, owing presumably to the animal's tissues having overcome them. In 1909 I repeated Blandini's experiments and obtained precisely similar results. A loopful of the $B$. prodigiosus was placed in the urethra of a guineapig, which was killed at the end of 10-16 hours. A post-mortem was conducted on the guinea-pig under aseptic conditions, and agar tubes inoculated with portions of tissue removed from various parts of the urinary tract. My results confirmed those of Blandini.

The table gives the results of the first four experiments.

Table of Results of Four Inoculations of B. Prodigiosus into Anterior Urethra of Guinea-pigs.

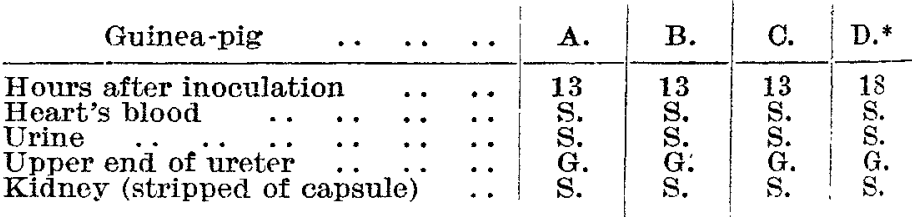

$$
\text { S. = Sterile. G. }=\text { Growth. }
$$

* The inoculation was also made into the posterior urethra.

The results of the four experiments were absolutely consistent. In every case the organisms were easily obtained from the upper extremity of the ureters, but no growth was obtained from the kidney; the urine and heart's blood were always free from organisms; there could be no doubt that the organisms placed in the urethra were able to make their way rapidly to the upper end of the ureter. The next step in the investigation was to discover the path by which they travelled. It was also desirable to find out whether they reached their position in virtue of their own powers of movement or were swept there by some outside agency.

Investigation of Power or Agency of Movement.

With a view to obtaining an answer to this question I substituted inorganic granules for living organisms, inoculating the anterior urethra with carmine granules, or with finely-powdered ferrous carbonate. The guinea-pig was killed at the end of 12 hours, and sections cut of the upper end of the ureter and of the kidney. Where ferrous carbonate had been employed 